\title{
Laparoscopic and endoscopic cooperative surgery for difficult resection of posterior esophagogastric junction gastrointestinal stromal tumors
}

The esophagogastric junction (EGJ) is a rare location for gastrointestinal stromal tumors (GIST) and resection remains challenging in posterior/fundic lesions [1]. Laparoscopic and endoscopic cooperative surgery (LECS) is a new combined minimally invasive method [2-4]. Recently, a large series of 126 patients who underwent LECS for gastric submucosal tumors (86 GISTs) was published showing a high rate of feasibility and less than $5 \%$ morbidity [5]. We report our experience in difficult gastric GIST resections.

Three patients underwent the procedure for posterior EG] GISTs with various symptomatology. The absence of metastasis and the location of the GIST were confirmed by esophagogastroscopy and computed tomography scan (\Fig.1). All procedures were performed under general anesthesia and with orotracheal intubation. The LECS steps were (\Fig.2, (\Video 1): 1) exposing the esophagus and liberating the angle of His by laparoscopy; 2) full-thickness incision around the tumor by endoscopy (Hook knife; Olympus, Tokyo, Japan); 3) exposure of the tumor pedicle to the surgeon (forceps); 4) laparoscopic resection with linear stapler; 5) gastrotomy suturing.
All LECS procedures were performed successfully in a mean time of 107 minutes (range 90-120 minutes). The blood loss was very low and did not require any blood transfusion. There were no immediate perioperative complications such as spleen wound, pneumothorax, vagus nerve injury, or any other adverse event. The mean tumor size was $5.3 \mathrm{~cm}$, with the largest diameter measuring $5.5 \mathrm{~cm}$, $4.5 \mathrm{~cm}$, and $6 \mathrm{~cm}$, respectively, and with Miettinen grade considered as low or very low risk of recurrence. The mean fasting duration, including nasogastric
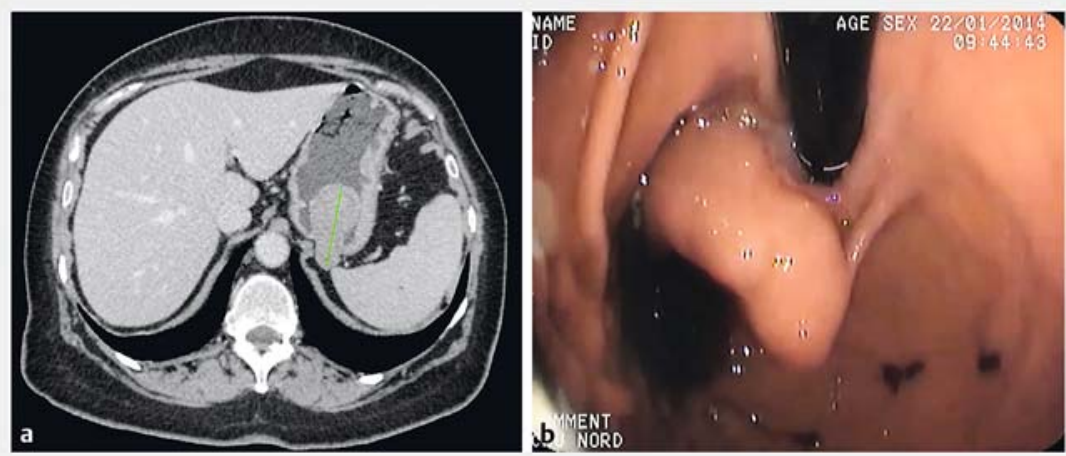

- Fig. 1 Radiological and endoscopic view of a fundic gastrointestinal stromal tumor. a Computed tomography scan showing a stromal esophagogastric junction tumor of $5.2 \mathrm{~cm}$. b Endoscopic retrograde view of the intraluminal part of the tumor.

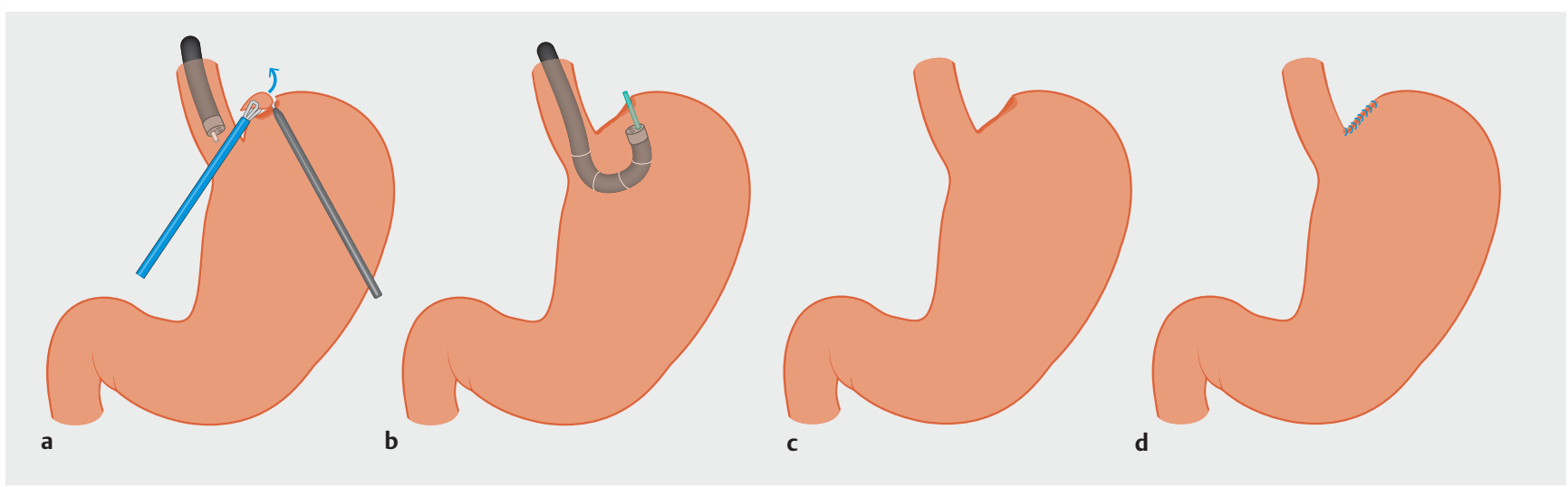

- Fig. 2 Steps of laparoscopic and endoscopic cooperative surgical technique for esophagogastric junction (EGJ) gastrointestinal stromal tumor resection. a Tumor location. b Endoscopic intraluminal resection using monopolar electrocoagulation and retrograde view. c Laparoscopic intraperitoneal final resection of the tumor using a linear stapler. $\mathbf{d}$ Gastrotomy laparoscopic interrupted suture ends the procedure. 


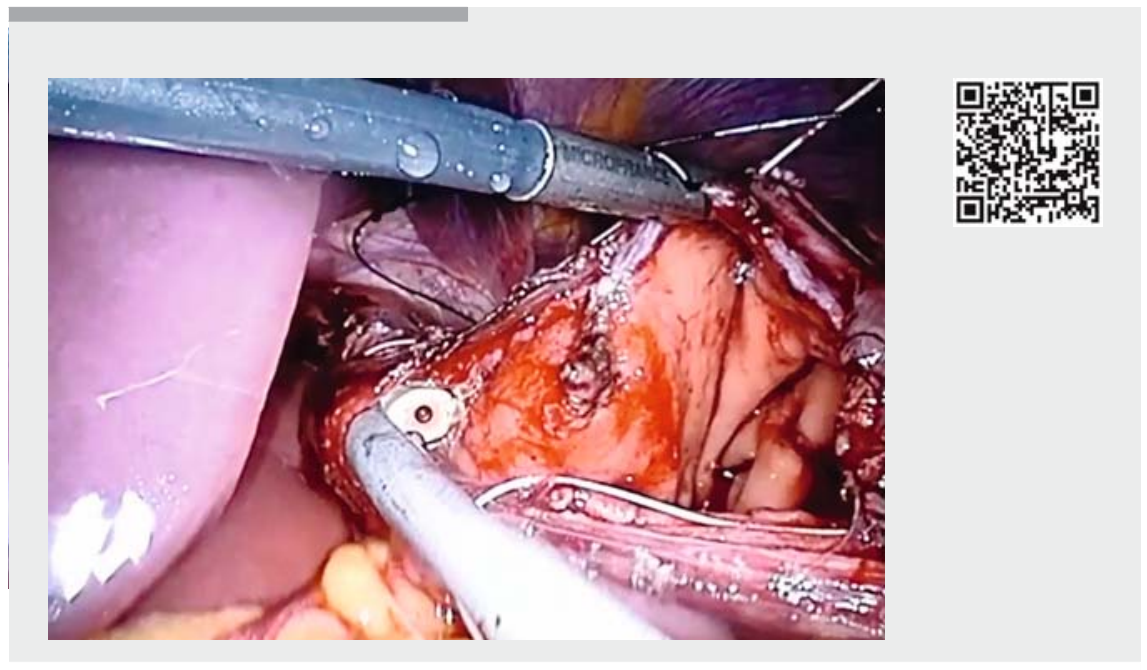

Video 1 Endoscopic intraluminal dissection of the tumor using carbohydrate gas. Transmural dissection of all layers of the stomach around the tumor was progressively and carefully performed using a diathermic electrosurgical knife. Laparoscopic resection of the tumor using a linear stapler. Tumor could then be removed in a bag and extracted by one of the port orifices.

\section{Competing interests}

Professor Barthet is a consultant for Boston Scientific.

The authors

Jean-Michel Gonzalez ${ }^{1}$, Antoine Debourdeau', Guillaume Philouze ${ }^{1}$, Laura Beyer ${ }^{2}$, Stéphane Berdah $^{2}$, Marc Barthet ${ }^{1}$

1 Department of Gastroenterology, Assistance Publique Hopitaux de Marseille, Aix-

Marseille Université, Hôpital Nord, Marseille, France

2 Department of Digestive Surgery, Assistance Publique Hopitaux de Marseille, Aix-

Marseille Université, Hôpital Nord, Marseille, France

\section{Corresponding author}

Jean-Michel Gonzalez, MD

Départment of Gastroenterology, AP-HM, Aix-Marseille Université, Hôpital Nord,

Marseille, France

Fax: +33-4-91968737

jmgonza05@yahoo.fr

\section{References}

[1] Blay J-Y, Bonvalot S, Casali P et al. GIST consensus meeting panellists. Consensus meeting for the management of gastrointestinal stromal tumors. Report of the GIST Consensus Conference of 20-21 March 2004, under the auspices of ESMO. Ann Oncol 2005; 16: $566-578$

[2] Chen K, Zhou Y-C, Mou Y-P et al. Systematic review and meta-analysis of safety and effi- cacy of laparoscopic resection for gastrointestinal stromal tumors of the stomach. Surg Endosc 2015; 29: 355-367

[3] Hiki N, Yamamoto Y, Fukunaga T et al. Laparoscopic and endoscopic cooperative surgery for gastrointestinal stromal tumor dissection. Surg Endosc 2008; 22: 1729-1735

[4] Ntourakis D, Mavrogenis G. Cooperative laparoscopic endoscopic and hybrid laparoscopic surgery for upper gastrointestinal tumors: current status. World I Gastroenterol 2015; 21: $12482-12497$

[5] Matsuda T, Nunobe S, Kosuga T et al. Society for the Study of Laparoscopy and Endoscopy Cooperative Surgery. Laparoscopic and luminal endoscopic cooperative surgery can be a standard treatment for submucosal tumors of the stomach: a retrospective multicenter study. Endoscopy 2017; 49: 476 483

\section{Bibliography}

DOI https://doi.org/10.1055/s-0043-121136

Published online: 14.11.2017

Endoscopy 2018; 50: 178-179

(c) Georg Thieme Verlag KG

Stuttgart $\cdot$ New York

ISSN 0013-726X

\section{ENDOSCOPY E-VIDEOS}

https://eref.thieme.de/e-videos

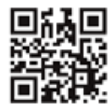

Endoscopy E-Videos is a free access online section, reporting on interesting cases and new

techniques in gastroenterological endoscopy. All papers include a high quality video and all contributions are freely accessible online.

This section has its own submission website at

https://mc.manuscriptcentral.com/e-videos 